OPEN ACCESS

Edited by:

Tianhui Chen,

University of Chinese Academy of

Sciences, China

Reviewed by:

Xinjun Li,

Lund University, Sweden

Galya Bigman,

Baltimore VA Medical Center,

United States

*Correspondence:

Jin-hu Fan

fanjh@cicams.ac.cn

You-lin Qiao,

qiaoy@cicams.ac.cn

${ }^{\dagger}$ These authors have contributed equally to this work

Specialty section:

This article was submitted to

Cancer Epidemiology

and Prevention,

a section of the journal

Frontiers in Oncology

Received: 11 September 2020

Accepted: 07 May 2021

Published: 28 May 2021

Citation:

Yang $H$, Wang J-b, Zhang J-y, Fan J-h, Qiao Y-I and Taylor PR (2021)

Family History and Risk of Upper

Gastrointestinal Cancer in the

Linxian General Population.

Front. Oncol. 11:605106.

doi: 10.3389/fonc.2021.605106

\section{Family History and Risk of Upper Gastrointestinal Cancer in the Linxian General Population}

\author{
Huan Yang ${ }^{1+}$, Jian-bing Wang ${ }^{2 \dagger}$, Jin-yu Zhang ${ }^{1}$, Jin-hu Fan ${ }^{1 *}$, You-lin Qiao ${ }^{1 *}$ \\ and Philip R. Taylor ${ }^{3}$
}

${ }^{1}$ Department of Cancer Epidemiology, National Cancer Center/National Clinical Research Center for Cancer/Cancer Hospital, Chinese Academy of Medical Sciences and Peking Union Medical College, Beijing, China, ${ }^{2}$ Department of Epidemiology and Biostatistics, The Children's Hospital, National Clinical Research Center for Child Health, Zhejiang University School of Medicine, Hangzhou, China, ${ }^{3}$ Metabolic Epidemiology Branch, Division of Cancer Epidemiology \& Genetics, National Cancer Institute, National Institutes of Health, Bethesda, MD, United States

Objective: The objective of this study was to investigate family history (FH) of upper gastrointestinal (UGl) cancer and risk of esophageal squamous cell carcinoma (ESCC), gastric cardia carcinoma (GCC), and gastric non-cardia carcinoma (GNCC) in the Linxian General Population Nutrition Intervention Trial (NIT) cohort. Methods: This prospective analysis was conducted using the Linxian NIT cohort data. Subjects with FH of UGl cancer was treated as an exposed group while the remainders were considered as a comparison group. Hazard ratios (HRs) and 95\% confidence intervals (Cls) for the association between $\mathrm{FH}$ of UGI cancer and risk of UGI cancer incidence and mortality were estimated using Cox proportional hazards models.

Results: There were 5,680 newly diagnosed UGl cancer cases during the follow-up period, with a total of 4,573 UGI cancer deaths occurred, including 2,603 ESCC, 1,410 GCC, and 560 GNCC deaths. A positive FH of UGl cancer was associated with a significantly increased risk of ESCC and GCC (Incidence: $\mathrm{HR}_{\mathrm{ESCC}}=1.45,95 \% \mathrm{Cl}$ : 1.35 1.56; $\mathrm{HR}_{\mathrm{GCC}}=1.27,95 \% \mathrm{Cl}: 1.15-1.40$; Mortality: $\mathrm{HR}_{\mathrm{ESCC}}=1.40,95 \% \mathrm{Cl}: 1.30-1.52$; $\left.\mathrm{HR}_{\mathrm{GCC}}=1.27,95 \% \mathrm{Cl}: 1.14-1.42\right)$ after adjusting for age at baseline, gender, smoking status, alcohol drinking, education level, and frequency of fresh fruit and vegetable consumption. Subjects with $\mathrm{FH}$ in both parents had the highest risk of ESCC and GCC incidence $\left(\mathrm{HR}_{\mathrm{ESCC}}=1.65,95 \% \mathrm{Cl}: 1.40-1.95 ; \mathrm{HR}_{\mathrm{GCC}}=1.42,95 \% \mathrm{Cl}: 1.12-1.81\right)$ and deaths $\left(H_{E S C C}=1.65,95 \% C l: 1.38-1.97 ; H_{G C C}=1.42,95 \% C l: 1.09-1.85\right)$. Spouse diagnosed with UGl cancer did not increase the risk of any UGl cancers of the subjects. In subgroup analysis, FH of UGl cancer was shown to significantly increase the risk of GCC in non-drinkers (Incidence: $\mathrm{HR}=1.31,95 \% \mathrm{Cl}: 1.17-1.47$; Mortality: $\mathrm{HR}=1.33$, 95\%Cl: 1.17-1.50). No associations were observed for risk of GNCC. Sensitivity analysis by excluding subjects who were followed up less than three years did not materially alter our results. 


\section{Conclusion: Our data point to the role of the FH of UGI cancer to the risk of ESCC and GCC incidence and mortality. The influence of family history on the risk of UGI cancer} varies from different types of family members.

Keywords: family history, risk factors, upper gastrointestinal cancer, cohort study, Linxian

\section{INTRODUCTION}

Upper gastrointestinal (UGI) cancer, including gastric and esophageal cancers, is among the top five leading causes of cancer mortality in China (1). However, considerable differences of UGI cancer incidence exist based on geographic and racial differences, which can be linked to differences in risk factors $(2,3)$. In Western countries, incidence rates of adenocarcinomas of the esophagus (EA) and gastric cardia (GCA) have been rising rapidly, which may be related to obesity, smoking, and gastroesophageal reflux disease (4). Compared with adenocarcinoma, esophageal squamous cell carcinoma (ESCC) and gastric cardia carcinoma (GCC) are more common in China, but their causes remain poorly defined.

The occurrence and development of gastrointestinal cancer result from both environmental and genetic factors (2). Previous studies conducted in China have reported that patients with ESCC who had a positive FH of UGI cancer had significantly different gene expression compared with sporadic cases, suggesting that these two types of patients have different genetic backgrounds (5). It has been also reported that factors such as lifestyle and diet habits had an impact on the long-term risk of UGI cancer $(6,7)$. In etiological research, it is often difficult to distinguish the independent impact of risk factors. Therefore, exploring the combined effects of environmental factors and genetic factors on diseases and analyzing their interaction is very important to cancer prevention in high-risk regions. A family history (FH) of cancer can assist in assessing risk for cancer development, which could represent the effects of both environmental and genetic factors. The American Society of Clinical Oncology (ASCO) recommended that oncologists seeing a new patient should take a family history, specifically asking about cancer in first- and second-degree relatives, to clarify the individual's risk (8). There is evidence that gastrointestinal cancer such as esophageal cancer, gastric cancer, and colorectal cancer have stronger familial clustering, which could more likely happen in high incidence regions (9-11). Familial esophageal cancer could have a worse prognosis than sporadic esophageal cancer (12). According to a systemic review, some findings of retrospective studies conducted in Europe, East Asia, India, and the United States all verified the association between FH and the risk of gastric cancer mortality (13). However, most of the results were based on case-control studies. Besides, since the environment and lifestyle could be different in high-risk regions, as well as racial differences, conclusions applicable to the general population may not be generalized to high-risk population. Long-time follow-up studies conducting in other high-incidence areas are needed to confirm the reliability of the evidence.
Linxian of Henan Province is one of the high-incidence regions of UGI cancer in China, with a mortality rate exceeding the Chinese average by 10 -fold and the American average (in white men) by 100-fold (14). In 1985, Linxian Nutrition Intervention Trial (NIT), the first randomized, double-blind, placebo-controlled nutritional intervention trial, was conducted to explore whether combinations of vitamins and minerals supplements could reduce cancer incidence and mortality. We assumed that $\mathrm{FH}$ could increase the risk of UGI cancers (including ESCC, GCC and gastric non-cardia carcinoma (GNCC) in Linxian. Herein, using 30-year followup data of the Linxian NIT cohort, we examined the association between a positive history of UGI cancer in a first-degree relative and risk of UGI cancer.

\section{MATERIALS AND METHODS}

\section{Study Population}

The study design of NIT cohort has been described before (15, 16). In brief, a total of 29,584 adults aged 40 to 69 years were recruited from four northern communes (Yaocun, Rencun, Donggang and Hengshui) in Linxian. Types of nutritional interventions include: A (retinol/zinc), B (riboflavin/niacin), C (vitamin $\mathrm{C} /$ molybdenum), and/or D (selenium/vitamin E/betacarotene), or placebo. After a pre-intervention survey, participants were randomly assigned to one of eight intervention groups, which received daily supplementations including $\mathrm{AB}, \mathrm{AC}, \mathrm{AD}, \mathrm{BC}, \mathrm{BD}, \mathrm{CD}, \mathrm{ABCD}$, or placebo (16). This $2^{4}$ fractional design can guarantee that half of the subjects received each of the four factors intervention while half of the subjects did not. These daily supplementations lasted for 5.25 years (from March 1986 to May 1991) and doses of the supplement were typically 1.5 to three times the US Recommended Dietary Allowance.

\section{Family History and Other Exposure Data at Baseline}

A baseline questionnaire survey was conducted to collect and assess baseline characteristics and exposure data, including demographic information, lifestyle, dietary habits, $\mathrm{FH}$ of cancer, and history of other major diseases. All subjects underwent a brief physical examination to assess their health status. Subjects were asked if their first-degree relatives (parents, siblings, children, and spouses) have been diagnosed with any cancer. Family history of UGI cancer was considered positive if subject had at least one first-degree relative with a history of esophageal or gastric cancer. Smoking was defined as regular cigarettes or hookah or pipe use at least weekly for six months, 
and alcohol drinking was defined as any alcohol consumed in the previous 12 months. Dietary information included frequency of persimmon bread, moldy bread, foods cooked in oil, meats, eggs, fruit, and vegetable consumption. To avoid the bias caused by seasonal effect, we calculated the frequency of fresh fruit and vegetable consumption in winter/spring and summer/autumn seasons separately.

\section{Follow-Up of Cancer}

During the trial period (1986-1991), village doctors contacted all subjects monthly, and all endpoints were confirmed by an International Endpoints Review Committee (a panel of American and Chinese senior experts). Village investigators continued to contacted participants monthly, and new cancer cases and deaths were confirmed by an international diagnostic team (a panel of American and Chinese diagnosticians, 19911996) or senior Chinese experts from Beijing (1996 to 2016). In our study, primary endpoints were ESCC, GNCC, and GCC deaths. GCC was defined as cancer that occurred in the most proximal $3 \mathrm{~cm}$ of the stomach and the gastroesophageal junction, and those originated elsewhere in the stomach were defined as GNCC (14).

\section{Statistical Analysis}

Differences in baseline demographic characteristics between FH of UGI cancer categories were compared using Chi-square test for categorical variables and nonparametric test for continuous variables. Participants were censored at the last known followup date, lost date of follow-up, date of death, or the closure date for the study (March 2016), whichever came first. Multivariable Cox proportional hazards regression models were used to calculate hazard ratios (HRs) and 95\% confidence intervals (95\% CI) for the association between FH of UGI and risk of UGI cancer incidence and mortality. Potential covariates in models included: age at baseline (continuous), gender (men or women), smoking status (yes or no), alcohol drinking (yes or no), education level (never, less than 5 years education, primary school, or higher education, and unknown), and frequency of fresh fruit and vegetable consumption (times/year). Subgroup analyses were performed to assess whether the association varied by age at baseline, sex, smoking and alcohol drinking. Sensitivity analyses were also conducted by exclusion of individuals who were followed up less than three years. Cumulative incidence and mortality rates of two groups were estimated by the method of Kaplan-Meier. Log-rank tests were used to examine the significance between cumulative incidence and mortality curves. Statistical analyses were performed using SPSS 23.0. All tests were two sided, and $P<0.05$ was considered statistically significant.

\section{Ethics Statement}

The NIT study was approved by the Institutional Review Boards of the United States (US) National Cancer Institute and Cancer Hospital, Chinese Academy of Medical Sciences (CHCAMS). After being informed of the procedure, general aim, possible benefits, and risks of the study at enrollment, all participants signed the informed consent form as evidence of their willingness to participate in this study. All study procedures followed the Helsinki Declaration.

\section{RESULTS}

After excluding subjects with incomplete baseline data and lost to follow-up, a total of 29,553 participants were included in the final analysis (Supplementary Figure). During the 30-year follow-up, a total of 588,401 person-years of follow-up were accumulated, with the median follow up time was $22.56(0.50-$ 30.08) years. Baseline demographic characteristics, smoking and alcohol drinking status, and frequency of fresh fruit and vegetable consumption for all subjects are shown in Table 1 according to the FH of UGI cancer categories. Relative to individuals without $\mathrm{FH}$ of UGI cancer, participants with a positive $\mathrm{FH}$ were mostly men (45.7\%), smokers (31.5\%), alcohol drinkers (25.6\%), and more likely to have higher education level. Most of characteristics varied significantly between the two FH categories $(P<0.05)$, except for age at baseline, consumption of fresh fruit and vegetable, and all intervention factors $(P>0.05)$.

There were 5,680 newly diagnosed UGI cancer cases during the follow-up period, with a total of 4,573 UGI cancer deaths occurred, including 2,603 ESCC, 1,410 GCC, and 560 GNCC deaths. Table 2 presents the associations between $\mathrm{FH}$ and risk of UGI cancer incidence and mortality. Participants with $\mathrm{FH}$ had a 44 and $27 \%$ higher risk of ESCC and GCC incidence $\left(\mathrm{HR}_{\mathrm{ESCC}}=\right.$ 1.44, 95\%CI: $1.34-1.55 ; \mathrm{HR}_{\mathrm{GCC}}=1.27,95 \% \mathrm{CI}: 1.15-1.40$ ), as well as a 39 and $26 \%$ higher risk of ESCC and GCC mortality compared with those without $\mathrm{FH}$, respectively $\left(\mathrm{HR}_{\mathrm{ESCC}}=1.39\right.$, 95\%CI: 1.28-1.50; $\mathrm{HR}_{\mathrm{GCC}}=1.26$, 95\%CI: 1.13-1.40). After adjusting for gender and age at baseline, risk of ESCC mortality in participants with $\mathrm{FH}$ was significantly increased by $40 \%\left(\mathrm{HR}_{\mathrm{ESCC}}=1.40,95 \% \mathrm{CI}: 1.29-1.51\right)$. Higher risk of ESCC and GCC incidence $\left(\mathrm{HR}_{\mathrm{ESCC}}=1.45,95 \% \mathrm{CI}: 1.35-1.56 ; \mathrm{HR}_{\mathrm{GCC}}=\right.$ 1.27, 95\%CI: $1.15-1.40)$ and mortality $\left(\mathrm{HR}_{\mathrm{ESCC}}=1.40,95 \% \mathrm{CI}\right.$ : $1.30-1.52 ; \mathrm{HR}_{\mathrm{GCC}}=1.27,95 \% \mathrm{CI}: 1.14-1.42$ ) were also observed after adjusting for age at baseline, gender, smoking status, alcohol drinking, education level, and frequency of fresh fruit and vegetable consumption (times/year). No association was observed for FH of UGI cancer and long-term risk of GNCC incidence and mortality.

Table 3 presents risk of ESCC, GCC, and GNCC according to family members. Positive FH of both parents and siblings was significantly associated with the increased incidence and mortality of ESCC (Incidence: $\mathrm{HR}_{\text {father }}=1.36$, 95\%CI: $1.24-$ $1.49 ; \mathrm{HR}_{\text {mother }}=1.53,95 \% \mathrm{CI}: 1.40-1.68 ; \mathrm{HR}_{\text {both parents }}=1.65$, 95\%CI 1.40-1.95; $\mathrm{HR}_{\text {brother }}=1.28,95 \% \mathrm{CI}: 1.09-1.51 ; \mathrm{HR}_{\text {sister }}=$ 1.41, 95\%CI: $1.15-1.73 ; \mathrm{HR}_{\text {siblings }}=1.33,95 \% \mathrm{CI}: 1.16-1.52$; Mortality: $\mathrm{HR}_{\text {father }}=1.35,95 \% \mathrm{CI}: 1.22-1.49 ; \mathrm{HR}_{\text {mother }}=1.48$, 95\%CI:1.34-1.63; $\mathrm{HR}_{\text {both parents }}=1.65,95 \% \mathrm{CI} 1.38-1.97$; $\mathrm{HR}_{\text {brother }}=1.33,95 \% \mathrm{CI}: 1.12-1.57 ; \mathrm{HR}_{\text {sister }}=1.35,95 \% \mathrm{CI}$ : 1.09-1.68; $\left.\mathrm{HR}_{\text {siblings }}=1.34,95 \% \mathrm{CI}: 1.16-1.54\right)$ and GCC (Incidence: $\mathrm{HR}_{\text {father }}=1.25,95 \% \mathrm{CI}: 1.11-1.42 ; \mathrm{HR}_{\text {mother }}=1.23$, 95\%CI: 1.08-1.40; $\mathrm{HR}_{\text {both parents }}=1.42,95 \% \mathrm{CI}: 1.12-1.81$; $\mathrm{HR}_{\text {brother }}=1.31,95 \% \mathrm{CI}: 1.06-1.63 ; \mathrm{HR}_{\text {sister }}=1.36,95 \% \mathrm{CI}$ : 1.04-1.79; $\mathrm{HR}_{\text {siblings }}=1.33,95 \% \mathrm{CI}: 1.11-1.59 ;$ Mortality: $\mathrm{HR}_{\text {father }}=1.25,95 \% \mathrm{CI}: 1.09-1.44 ; \mathrm{HR}_{\text {mother }}=1.23,95 \% \mathrm{CI}$ : $1.07-1.42 ; \mathrm{HR}_{\text {both parents }}=1.42,95 \% \mathrm{CI} 1.09-1.85 ; \mathrm{HR}_{\text {brother }}=$ 1.29, 95\%CI: $1.02-1.63 ; \mathrm{HR}_{\text {siblings }}=1.26,95 \% \mathrm{CI}: 1.03-1.53$ ), 
TABLE 1 | Baseline demographic characteristics by family history of UGI cancer in the Linxian General Population NIT Cohort.

\begin{tabular}{|c|c|c|c|c|c|}
\hline & $\begin{array}{l}\text { No family history of UGI cancer } \\
\qquad(N=20,110)\end{array}$ & $\%$ & $\begin{array}{l}\text { Family history of UGI cancer } \\
\qquad(N=9,443)\end{array}$ & $\%$ & $P$ value* \\
\hline Age at baseline, years & & & & & 0.09 \\
\hline$<55$ & 11,951 & 59.4 & 5,711 & 60.5 & \\
\hline$\geq 55$ & 8,159 & 40.6 & 3,732 & 39.5 & \\
\hline Gender & & & & & $<0.01$ \\
\hline Women & 11,246 & 55.9 & 5,132 & 54.3 & \\
\hline Men & 8,864 & 44.1 & 4,311 & 45.7 & \\
\hline Smoking $^{\dagger}$ & & & & & $<0.01$ \\
\hline No & 14,148 & 70.7 & 6,465 & 68.5 & \\
\hline Yes & 5,858 & 29.3 & 2,978 & 31.5 & \\
\hline Alcohol Drinking ${ }^{\ddagger}$ & & & & & $<0.01$ \\
\hline No & 15,511 & 77.5 & 7,024 & 74.4 & \\
\hline Yes & 4,495 & 22.5 & 2,418 & 25.6 & \\
\hline Education level $^{\ddagger}$ & & & & & $<0.01$ \\
\hline Never & 8,187 & 40.9 & 3,625 & 38.4 & \\
\hline Less than 5 years education & 6,223 & 31.1 & 2,961 & 31.4 & \\
\hline Primary school or higher education & 3,843 & 19.2 & 2,011 & 21.3 & \\
\hline Unknown & 1,753 & 8.8 & 846 & 9.0 & \\
\hline Commune & & & & & $<0.01$ \\
\hline Yaocun & 6,783 & 33.7 & 3,163 & 33.5 & \\
\hline Rencun & 3,716 & 18.5 & 2,240 & 23.7 & \\
\hline Donggang & 4,346 & 21.6 & 1,914 & 20.3 & \\
\hline Hengshui & 5,265 & 26.2 & 2,126 & 22.5 & \\
\hline Retinol/zinc supplements & & & & & 0.40 \\
\hline No & 10,028 & 49.9 & 4,758 & 50.4 & \\
\hline Yes & 10,082 & 50.1 & 4,685 & 49.6 & \\
\hline Riboflavin/niacin supplements & & & & & 0.39 \\
\hline No & 10,008 & 49.8 & 4,750 & 50.3 & \\
\hline Yes & 10,102 & 50.2 & 4,693 & 49.7 & \\
\hline Vitamin $\mathrm{C} /$ molybdenum supplements & & & & & 0.88 \\
\hline No & 10,060 & 50.0 & 4,715 & 49.9 & \\
\hline Yes & 10,050 & 50.0 & 4,728 & 50.1 & \\
\hline Selenium/vitamin E/beta-carotene supplements & & & & & 0.40 \\
\hline No & 10,028 & 49.9 & 4,758 & 50.4 & \\
\hline Yes & 10,082 & 50.1 & 4,685 & 49.6 & \\
\hline Fresh vegetable consumption, median (IQR), times/year ${ }^{\dagger}$ & $730.0(547.5-912.5)$ & & $730.0(547.5-912.5)$ & & 0.34 \\
\hline Fresh fruit consumption, median (IQR), times/year ${ }^{\dagger}$ & $6.0(2.0-15.0)$ & & $6.0(2.0-13.0)$ & & 0.90 \\
\hline
\end{tabular}

respectively. However, participants with $\mathrm{FH}$ in sisters did not have significantly higher risk of GCC mortality $\left(\mathrm{HR}_{\text {sister }}=1.14\right.$, 95\%CI: $0.83-1.57)$. No association of positive $\mathrm{FH}$ in spouse between any UGI cancer was observed.

Subgroup analysis for the association of $\mathrm{FH}$ with risk of ESCC, GNCC, and GCC incidence and mortality are shown in Tables 4 and 5. FH of UGI cancer could significantly increase the risk of GCC incidence $(\mathrm{HR}=1.31,95 \% \mathrm{CI}: 1.17-1.47)$ and mortality in non-drinkers $(\mathrm{HR}=1.33,95 \% \mathrm{CI}: 1.17-1.50)$. We observed that HRs were varied across strata by sex and smoking $\left(P_{\text {interaction }}<0.05\right)$ for risk of ESCC incidence and mortality, and appeared similar across subgroups by sex, smoking and alcohol drinking for risk of GCC and GNCC incidence and mortality $\left(P_{\text {interaction }}>0.05\right)$.

Cumulative incidence and mortality curves of ESCC, GCC, and GNCC by FH categories are presented in Figures $\mathbf{1}$ and 2. Compared with the control group, higher cumulative incidence rates (ESCC: $13.0 \%$ vs. $18.7 \%, P<0.01$; GCC: $7.8 \%$ vs. $10.0 \%$,
$P<0.01$ ) and mortality rates (ESCC: $11.5 \%$ vs. $16.0 \%, P<0.01$; GCC: $6.5 \%$ vs. $8.5 \%, P<0.01)$ of ESCC and GCC were observed in the positive $\mathrm{FH}$ group, and no significant difference was observed for GNCC incidence $(P=0.12)$ and mortality $(P=0.30)$.

To avoid reverse causation, sensitivity analysis was used to assess the stability of our results (Table 6). After exclusion of individuals who were followed up less than three years, HRs for the association between FH of UGI and risk of ESCC, GNCC, and GCC incidence and mortality did not materially change, indicating the robust results of the study analysis.

\section{DISCUSSION}

In our large population-based cohort study, we found that a $\mathrm{FH}$ of UGI cancer in first-degree relatives was associated with an increased risk of ESCC and GCC incidence and mortality. In the subgroup analyses, FH of UGI cancer could significantly increase 
TABLE 2 | Crude and adjusted hazards ratios (HRs) and 95\% confidence intervals (Cls) for the associations between family history of UGI cancer and risk of ESCC, GCC, and GNCC incidence, and mortality.

\begin{tabular}{|c|c|c|c|c|}
\hline & \multicolumn{2}{|c|}{ UGI Cancer Incidence } & \multicolumn{2}{|c|}{ UGI Cancer Mortality } \\
\hline & $\begin{array}{l}\text { No family history of UGI } \\
\text { cancer }\end{array}$ & $\begin{array}{l}\text { Positive family history of UGI } \\
\text { cancer }\end{array}$ & $\begin{array}{l}\text { No family history of UGI } \\
\text { cancer }\end{array}$ & $\begin{array}{l}\text { Positive family history of UGI } \\
\text { cancer }\end{array}$ \\
\hline \multicolumn{5}{|l|}{ ESCC } \\
\hline No. of cases/deaths & 1,874 & 1,239 & 1,583 & 1,020 \\
\hline Crude HR (95\%Cl) & 1 & $1.44(1.34-1.55)$ & 1 & $1.39(1.28-1.50)$ \\
\hline $\begin{array}{l}\text { Age and gender adjusted HR } \\
(95 \% \mathrm{Cl})\end{array}$ & 1 & $1.45(1.35-1.55)$ & 1 & $1.40(1.29-1.51)$ \\
\hline $\begin{array}{l}\text { Multivariable adjusted HR (95\% } \\
\mathrm{Cl})^{\dagger}\end{array}$ & 1 & $1.45(1.35-1.56)$ & 1 & $1.40(1.30-1.52)$ \\
\hline \multicolumn{5}{|l|}{ GNCC } \\
\hline No. of cases/deaths & 412 & 217 & 371 & 189 \\
\hline Crude HR (95\%Cl) & 1 & $1.14(0.97-1.35)$ & 1 & $1.10(0.92-1.31)$ \\
\hline $\begin{array}{l}\text { Age and gender adjusted HR } \\
(95 \% \mathrm{Cl})\end{array}$ & 1 & $1.14(0.96-1.34)$ & 1 & $1.10(0.92-1.31)$ \\
\hline $\begin{array}{l}\text { Multivariable adjusted HR (95\% } \\
\mathrm{Cl})^{\dagger}\end{array}$ & 1 & $1.14(0.96-1.34)$ & 1 & $1.10(0.92-1.31)$ \\
\hline \multicolumn{5}{|l|}{ GCC } \\
\hline No. of cases/deaths & 1,099 & 639 & 890 & 520 \\
\hline Crude HR (95\%Cl) & 1 & $1.27(1.15-1.40)$ & 1 & $1.26(1.13-1.40)$ \\
\hline $\begin{array}{l}\text { Age and gender adjusted HR } \\
(95 \% \mathrm{Cl})\end{array}$ & 1 & $1.26(1.14-1.39)$ & 1 & $1.26(1.13-1.40)$ \\
\hline $\begin{array}{l}\text { Multivariable adjusted HR (95\% } \\
\mathrm{Cl})^{+}\end{array}$ & 1 & $1.27(1.15-1.40)$ & 1 & $1.27(1.14-1.42)$ \\
\hline
\end{tabular}

ESCC, esophageal squamous cell carcinoma; GCC, gastric cardia carcinoma; GNCC, gastric non-cardia carcinoma; $\mathrm{HR}$, hazard ratio; 95\%Cl = 95\% confidence interval. ${ }^{\dagger}$ Adjusted for age at baseline, sex, smoking, alcohol drinking, education level, frequency of fresh fruit and vegetable consumption (times/year).

Bold text in this manuscript indicates statistical significance.

TABLE 3 | Risk of ESCC, GCC, and GNCC incidence/mortality according to the types of family members affected ${ }^{\dagger}$.

\begin{tabular}{|c|c|c|c|c|c|c|}
\hline & \multicolumn{3}{|c|}{ UGI Cancer IncidenceHRs $(95 \% \mathrm{Cl})$} & \multicolumn{3}{|c|}{ UGI Cancer MortalityHRs (95\%Cl) } \\
\hline & ESCC & GNCC & GCC & ESCC & GNCC & GCC \\
\hline Father & $1.36(1.24-1.49)$ & $1.27(1.03-1.56)$ & $1.25(1.11-1.42)$ & $1.35(1.22-1.49)$ & $1.20(0.96-1.50)$ & $1.25(1.09-1.44)$ \\
\hline Mother & $1.53(1.40-1.68)$ & $1.02(0.81-1.28)$ & $1.23(1.08-1.40)$ & $1.48(1.34-1.63)$ & $1.04(0.82-1.32)$ & $1.23(1.07-1.42)$ \\
\hline Both parents & $1.65(1.40-1.95)$ & $0.88(0.53-1.44)$ & $1.42(1.12-1.81)$ & $1.65(1.38-1.97)$ & $0.97(0.59-1.60)$ & $1.42(1.09-1.85)$ \\
\hline Brother & $1.28(1.09-1.51)$ & $0.96(0.64-1.45)$ & $1.31(1.06-1.63)$ & $1.33(1.12-1.57)$ & $0.85(0.54-1.33)$ & $1.29(1.02-1.63)$ \\
\hline Sister & $1.41(1.15-1.73)$ & $1.06(0.64-1.74)$ & 1.36 (1.04-1.79) & 1.35 (1.09-1.68) & $1.06(0.63-1.77)$ & $1.14(0.83-1.57)$ \\
\hline Siblings $s^{\ddagger}$ & $1.33(1.16-1.52)$ & $1.00(0.72-1.40)$ & $1.33(1.11-1.59)$ & $1.34(1.16-1.54)$ & $0.93(0.65-1.32)$ & $1.26(1.03-1.53)$ \\
\hline Spouse & $1.16(0.96-1.40)$ & $0.68(0.40-1.16)$ & $1.15(0.89-1.50)$ & $1.10(0.89-1.35)$ & $0.76(0.46-1.28)$ & $1.22(0.93-1.60)$ \\
\hline
\end{tabular}

ESCC, esophageal squamous cell carcinoma; GCC, gastric cardia carcinoma; GNCC, gastric non-cardia carcinoma; HR, hazard ratio; 95\%Cl, 95\% confidence interval.

${ }^{\dagger}$ Adjusted for age at baseline, sex, smoking, alcohol drinking, education level, frequency of fresh fruit and vegetable consumption (times/year).

${ }^{\ddagger}$ Family history of UGI cancer in sibling was defined as participants whose brother or sister has been diagnosed with UGI cancer.

Bold text in this manuscript indicates statistical significance.

the risk of GCC incidence (HR $=1.31,95 \% \mathrm{CI}: 1.17-1.47)$ and mortality in non-drinkers ( $\mathrm{HR}=1.33,95 \% \mathrm{CI}: 1.17-1.50)$. No associations were observed for FH of UGI cancer and risk of GNCC incidence and mortality.

Our findings for esophageal cancer were consistent with a similar study conducted in Yangcheng County, Shanxi Province (10), one of the high-risk regions of esophageal cancer in China, suggesting shared susceptibility in esophageal cancer pathogenesis including genetic and environmental factors. However, this study was at odds with reports from Western countries such as US and Sweden $(17,18)$, where individuals reporting no association between $\mathrm{FH}$ of any digestive cancer and risk of esophageal cancer. Possible reasons for this difference may be that squamous cell carcinoma is the most common pathological type of esophageal cancer in China, while adenocarcinoma is common in Western countries, which may lead to differences in genetic susceptibility. Furthermore, genetic factors are more prominent in the development of ESCC in China and family members are more likely to share environmental exposures closely such as diet.

ESCC is a polygenic hereditary disease that can be affected by genetic factors $(19,20)$. Heritability is defined as the fraction of variation in a phenotype that results from genetic factors in a population (21). Linxian is a high-incidence region of esophageal cancer in China, with an obvious familial aggregation phenomenon. The results of a case-control study showed that 
TABLE 4 | Subgroup analyses for family history of UGI cancer and risk of ESCC, GCC and GNCC incidence ${ }^{\dagger}$.

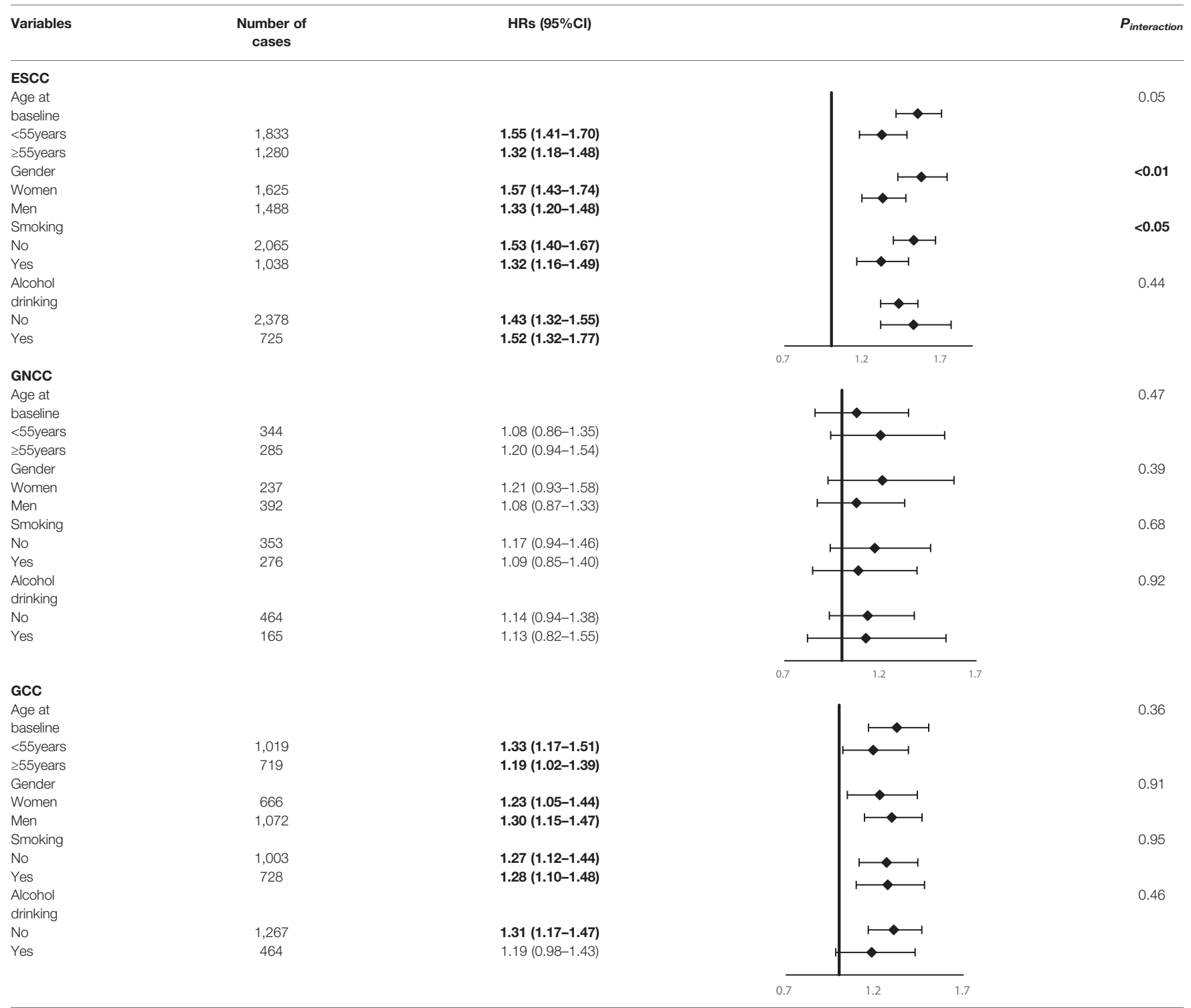

ESCC, esophageal squamous cell carcinoma; GCC, gastric cardia carcinoma; GNCC, gastric non-cardia carcinoma; HR, hazard ratio; 95\%Cl, 95\% confidence interval. ${ }^{\dagger}$ Adjusted for age at baseline, sex, smoking, alcohol drinking, education level, frequency of fresh fruit and vegetable consumption (times/year).

Bold text in this manuscript indicates statistical significance.

the heritability in Linxian (53.4\%) was higher than that of nonhigh-risk areas such as Xi' an (48.14\%) and Shanghai (35.7\%) (22), indicating that genetic factors may play a greater role in the incidence of esophageal cancer in Linxian than that in non-high incidence areas, and the existence of high incidence areas may be related to genetic factors. The population in Linxian has the following characteristics: 1) family members are concentrated in rural areas; 2) generations have lived in the same village for a long time; 3) low mobility; 4) similar environmental factors; 5) genetic background is clear and stable; 6) lots of family members.

The relationship between $\mathrm{FH}$ of cancer and risk of gastric cancer was mostly evaluated using case-control studies. Yaghoobi et al. reviewed case-control studies from 15 countries or regions (13), which consistently showed that gastric cancer history in first-or second-degree relatives was associated with risk of gastric cancer, and the results were not adjusted for risk factors such as age, gender, smoking, drinking, and BMI. There have been several prospective studies undertaken on the role of the FH of malignancy in the development of gastric cancer. A study conducted in Japan showed that a positive $\mathrm{FH}$ of cancer, especially stomach cancer, could increase the risk of stomach cancer deaths (23). Minkyo Song et al. indicated that family history of gastric cancer in first-degree relatives was associated with risk of gastric cancer (24), which agreed with our results. However, the positive rate of FH of UGI cancer in the Linxian general population was $32.0 \%$, largely higher than that in other 
TABLE 5 | Subgroup analyses for family history of UGI cancer and risk of ESCC, GCC and GNCC mortality ${ }^{\dagger}$.

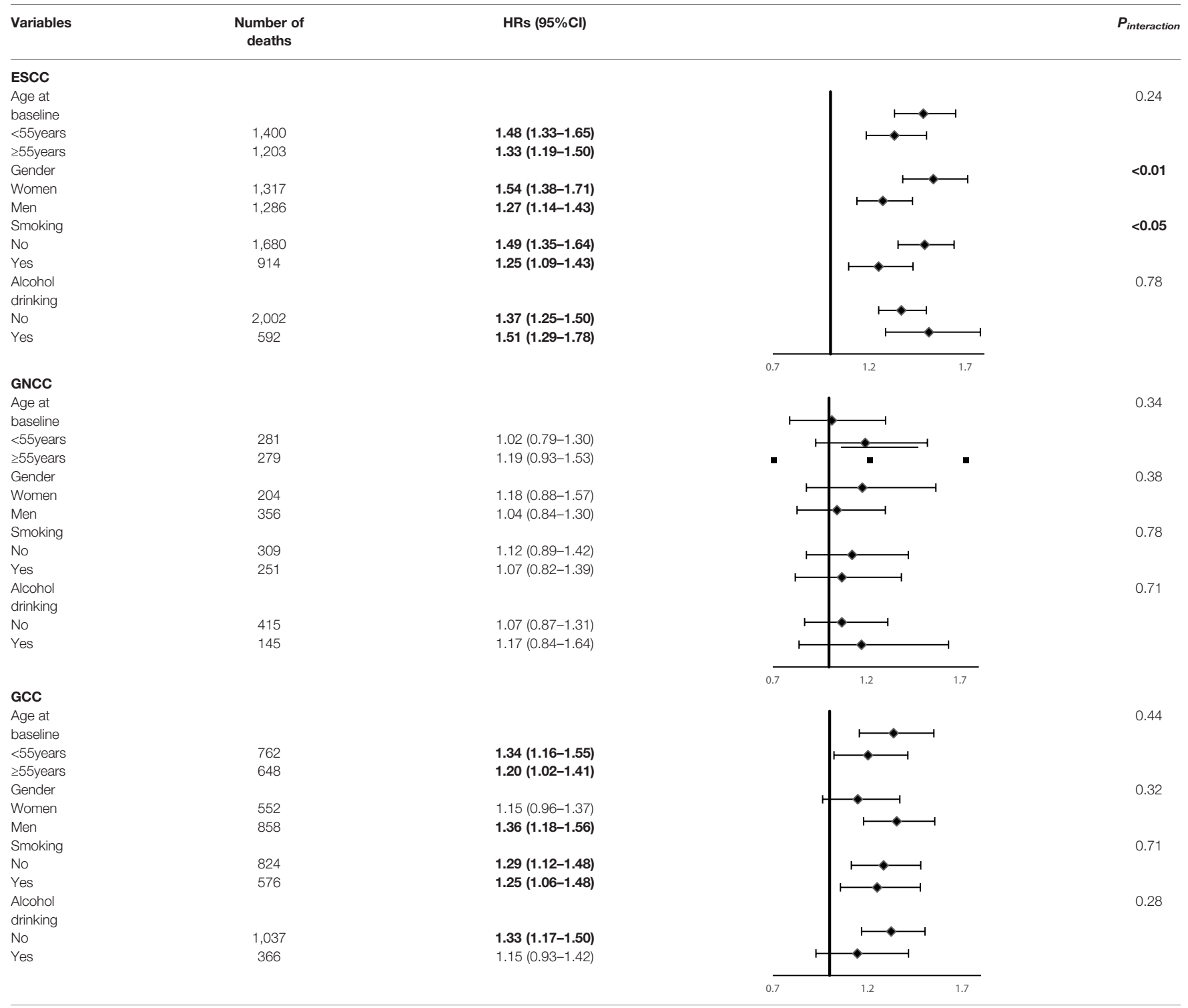

ESCC, esophageal squamous cell carcinoma; GCC, gastric cardia carcinoma; GNCC, gastric non-cardia carcinoma; HR, hazard ratio; 95\%Cl, 95\% confidence interval. ${ }^{\dagger}$ Adjusted for age at baseline, sex, smoking, alcohol drinking, education level, frequency of fresh fruit and vegetable consumption (times/year).

ESCC

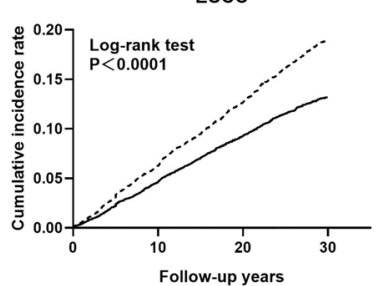

(A)
GCC

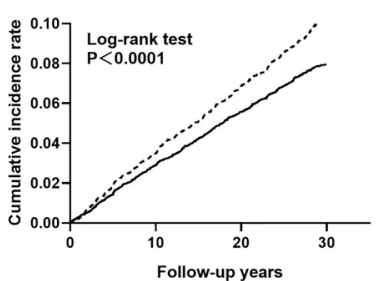

(B)
GNCC

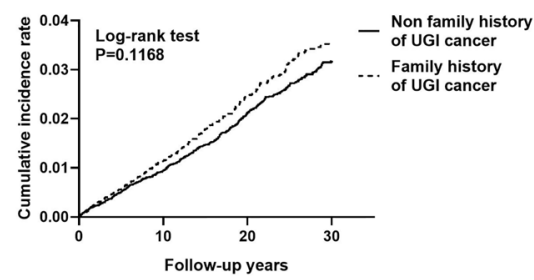

(C)

FIGURE 1 | Effect of family history of UGl cancer on cumulative incidence caused by ESCC (A), GCC (B), and GNCC (C). ESCC, esophageal squamous cell carcinoma; GCC, gastric cardia carcinoma; GNCC, gastric non-cardia carcinoma. 


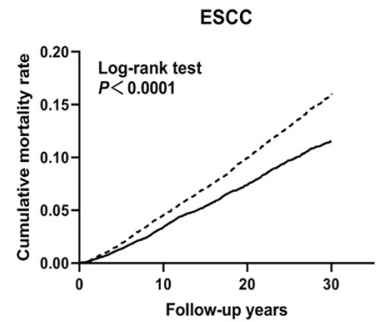

(A)

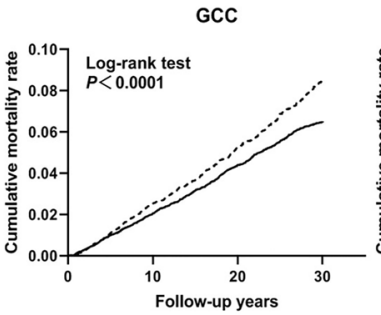

(B)

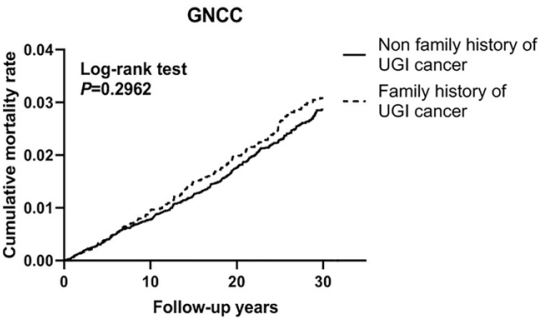

(C)

FIGURE 2 | Effect of family history of UGI cancer on cumulative mortality caused by ESCC (A), GCC (B), and GNCC (C). ESCC, esophageal squamous cell carcinoma; GCC, gastric cardia carcinoma; GNCC, gastric non-cardia carcinoma.

TABLE 6 | Sensitivity analysis by excluding individuals with less than 3 years follow up for the associations between family history of UGl cancer and risk of ESCC, GCC, and GNCC incidence and mortality.

UGI Cancer Incidence UGI Cancer Mortality

No family history of UGI Positive family history of UGI No family history of UGI Positive family history of UGI cancer cancer cancer cancer

ESCC

No. of cases/deaths

Crude HR $(95 \% \mathrm{Cl})$

Age and gender adjusted HR $(95 \% \mathrm{Cl})$

Multivariable adjusted $\mathrm{HR}(95 \% \mathrm{Cl})^{\dagger}$

\section{GNCC}

No. of cases/deaths

Crude HR $(95 \% \mathrm{Cl})$

Age and gender adjusted $\mathrm{HR}(95 \% \mathrm{Cl})$

Multivariable adjusted HR $(95 \% \mathrm{Cl})^{\dagger}$

GCC

No. of cases/deaths

Crude HR $(95 \% \mathrm{Cl})$

Age and gender adjusted $\mathrm{HR}(95 \% \mathrm{Cl})$

Multivariable adjusted HR $(95 \% \mathrm{Cl})^{\dagger}$

$\begin{array}{cc}1,534 & 1,008 \\ 1 & \mathbf{1 . 4 4}(\mathbf{1 . 3 4 - 1 . 5 6 )} \\ 1 & \mathbf{1 . 4 4}(\mathbf{1 . 3 4 - 1 . 5 6 )} \\ 1 & \mathbf{1 . 4 5}(\mathbf{1 . 3 5 - 1 . 5 7 )} \\ & \\ 334 & 173 \\ 1 & 1.13(0.94-1.35) \\ 1 & 1.12(0.94-1.34) \\ 1 & 1.12(0.93-1.34) \\ & \\ 877 & 507 \\ 1 & \mathbf{1 . 2 7}(\mathbf{1 . 1 4 - 1 . 4 1 )} \\ 1 & \mathbf{1 . 2 6}(\mathbf{1 . 1 3 - 1 . 4 0 )} \\ 1 & \mathbf{1 . 2 7}(\mathbf{1 . 1 4 - 1 . 4 1 )}\end{array}$

935

$1.39(1.28-1.51)$

$1.40(1.29-1.52)$

$1.40(1.29-1.52)$

170

$1.12(0.94-1.36)$

$1.13(0.94-1.36)$

$1.13(0.94-1.36)$

468

$1.28(1.14-1.43)$

$1.27(1.14-1.43)$

$1.29(1.15-1.45)$

ESCC, esophageal squamous cell carcinoma; GCC, gastric cardia carcinoma; GNCC, gastric non-cardia carcinoma; HR, hazard ratio; 95\%Cl, 95\% confidence interval.

${ }^{\dagger}$ Adjusted for age at baseline, sex, smoking, alcohol drinking, education level, frequency of fresh fruit and vegetable consumption (times/year).

Bold text in this manuscript indicates statistical significance.

countries such as Iran (5.6\%) (25), Spain (6.6\%) (26), and the US (4.3\%) (4). While most gastric cancers are sporadic, the phenomenon of familial aggregation occurs in about $10 \%$ of the gastric cancer cases, of which only $1-3 \%$ have a clear hereditary pattern (27), indicating that $\mathrm{FH}$ of gastric cancer reflects both environmental factors and genetic susceptibility that are shared within the family. Compared with Western countries, gastric cancer patients and their relatives in China are more likely to be exposed to the common living environment. In Western countries, the living environment does not cause excessive interference with family factors, and the positive rate of family history of gastric cancer may only reflect the role of genetic factors $(28,29)$.

Our results by anatomic sub-site of gastric cancer (cardia and non-cardia) showed that FH of UGI cancer was associated with increased risk of GCC only. GCC and GNCC are considered as a distinct type of gastric cancers due to their different risk factors for development and prognosis. In a study aiming to clarify the effects of life-style on gastric cancer by subsite focusing on the proximal part (cardia and fundus) and the distal part (pyloric antrum), a declining trend in the risk of gastric cancer was observed from the cardia to antrum (30). One possible explanation may be that the esophagus is anatomically adjacent to the gastric cardia, and it is reasonable to assume that some risk factors affect the cardia more easily than the distal parts (such as middle and antrum), therefore, the esophagus and gastric cardia may share some common etiological factors. Furthermore, GCC and GNCC have significantly different clinicopathological characteristics. A retrospective study showed that GCC patients had larger tumor diameters, higher invasion, and metastasis rates, and the five-year survival rate after a radical resection was significantly lower than that of GNCC patients (31).

In our study, we found higher risk of GCC incidence and mortality in subjects with UGI cancer history in parents compared with those with sisters affected. This finding was contrary to previous studies which suggested that individuals 
who had a sibling affected were at higher risk of gastric cancer $(32,33)$. The inconsistency between studies may be explained by the small number of subjects with siblings affected and random variation. Moreover, a positive $\mathrm{FH}$ in our study was defined as the subject had at least one first-degree relative with a history of UGI cancer, rather than gastric cancer only. Another possible explanation is that lifestyle and diet habits of parents have a greater impact on children than that of siblings. We found that $\mathrm{FH}$ in spouse could not increase the risk of any UGI cancer incidence and mortality. Compared with other types of relatives, subjects and their spouses were not related by blood. Lacking effect of genetic factor may be the potential reason of nonassociation between $\mathrm{FH}$ in spouse and the risk of UGI cancer. Further studies are needed to confirm the association between $\mathrm{FH}$ in different type of relatives and gastric cancer risk.

In the subgroup analyses, our results showed the interaction by sex and smoking status for the association between $\mathrm{FH}$ and ESCC incidence and mortality, which is contrary to the results of a previous study conducted in Shanxi Province (34). The possible reason may be that some potential confounding factors could not be fully adjusted in subgroup analyses among subjects of different genders or smoking status. For example, we observed the interaction between smoking status and $\mathrm{FH}$ of UGI cancer in men and found no interaction between smoking and FH in male subjects ( $P_{\text {interaction }}>0.05$, data not shown), which may help support our results. We observed the interaction between smoking status and FH of UGI cancer in men and found no interaction between smoking and $\mathrm{FH}$ in male subjects $\left(P_{\text {interaction }}>0.05\right.$, data not shown), which means that gender may affect the interaction between smoking status and FH of UGI cancer. Furthermore, differences in sample size and number of cases would also affect our results. Several studies have also explored potential difference in risk among patients with $\mathrm{FH}$ of gastric cancer in different genders. Yatsuya and his colleagues revealed that a positive $\mathrm{FH}$ of gastric cancer in one or more first-degree relatives might lead to elevated risk of gastric cancer mortality in both genders, whereas a higher risk was observed for women (35). However, studies in Iran (36) and Korea (37) reported higher survival rates of gastrointestinal tract cancer in women, which was consistent with our findings. According to baseline demographic characteristics in the Linxian general population (data not shown), men were more likely to be smokers and alcohol drinkers, indicating that women could have a better lifestyle and be more likely to have a lower risk of GCC, which may lead to increased survival and overestimated adverse effect caused by FH of UGI cancer (7). Until now, it is not verified whether smoking and alcohol drinking modify the association between FH of UGI cancer and gastric cancer mortality, and no effect modification was observed for gastric cancer in our study.

Although environmental factors play an initiating role during tumorigenesis, the occurrence of UGI cancer is caused by both genetic and environmental components. Single nucleotide polymorphisms (SNPs) are one of the most common types of genetic variations in the human genome. From a clinical perspective, SNPs are potential diagnostic and therapeutic biomarkers in UGI cancer (38-40). In recent years, molecular epidemiological studies have found that some enzymes related to the metabolism of carcinogens have genetic and phenotypic polymorphisms in the population, and individuals with different genes or phenotypes have different metabolic capabilities to environmental carcinogens, leading to differences in the probability of individual UGI cancer under the same environmental exposure $(41,42)$. This may suggest that genetic studies can help persons with an unknown FH of UGI to determine whether they are genetically susceptible to developing UGI cancer.

Our study has several strengths including large number of UGI cancer cases, long-term follow-up, and excellent compliance, which could contribute to more convincing conclusions. However, several limitations need to be noted. Firstly, the major limitation of this study was self-reported data on family history of UGI cancer, which could affect our findings. However, a previous study suggested that the sensitivity and specificity of self-reported family history was fairly good (43). Furthermore, in a prospective cohort study, inaccurate reporting of $\mathrm{FH}$ would produce non-differential misclassification that could bias the results towards the null. Secondly, this study was conducted in a nutritionally deprived population, leading to its conclusion may not be extrapolated to a well-nourished population. Thirdly, the study may have selection bias since it is a volunteer study where certain types of people tend to be recruited. Finally, some potential confounders such as Helicobacter pylori infection and socioeconomic status were not included in the analysis.

In summary, in this long-term prospective study, individuals with FH of UGI cancer had higher risk of ESCC and GCC incidence and mortality. For GCC, stronger association was observed for subjects with UGI cancer history in parents than that in siblings. Further studies need to be carried out in order to validate the specific mechanism of $\mathrm{FH}$ affecting the risk of UGI cancer.

\section{DATA AVAILABILITY STATEMENT}

The raw data supporting the conclusions of this article will be made available by the authors, without undue reservation.

\section{ETHICS STATEMENT}

The studies involving human participants were reviewed and approved by the Institutional Review Boards of Cancer Hospital, Chinese Academy of Medical Sciences. The patients/participants provided their written informed consent to participate in this study. Written informed consent was obtained from the individual(s) for the publication of any potentially identifiable images or data included in this article.

\section{AUTHOR CONTRIBUTIONS}

HY and J-BW contributed equally to this manuscript. Study concepts: Y-LQ, J-HF, and PT. Study design: Y-LQ, J-HF, 
and PT. Data acquisition: Y-LQ and J-HF. Quality control of data and algorithms: Y-LQ and J-HF. Data analysis and interpretation: $\mathrm{HY}$ and J-BW. Statistical analysis: $\mathrm{HY}$ and J-BW. Manuscript preparation: HY and J-BW. Manuscript editing: HY, J-BW, and J-YZ. Manuscript review: HY, J-BW, J-HF, J-YZ, Y-LQ, and PT. All authors contributed to the article and approved the submitted version.

\section{FUNDING}

This study was supported by a US National Cancer Institute contract (HHSN261201700047C) to the Cancer Hospital, Chinese Academy of Medical Sciences, China.

\section{REFERENCES}

1. Chen W, Zheng R, Baade PD, Zhang S, Zeng H, Bray F, et al. Cancer Statistics in China, 2015. CA Cancer J Clin (2016) 66(2):115-32. doi: 10.3322/ caac. 21338

2. Song X, Li W-Q, Hu N, Zhao XK, Wang Z, Hyland PL, et al. GWAS FollowUp Study of Esophageal Squamous Cell Carcinoma Identifies Potential Genetic Loci Associated With Family History of Upper Gastrointestinal Cancer. Sci Rep (2017) 7(1):4642. doi: 10.1038/s41598-017-04822-2

3. Domper Arnal MJ, Ferrández Arenas Á, Lanas Arbeloa Á. Esophageal Cancer: Risk Factors, Screening and Endoscopic Treatment in Western and Eastern Countries. World J Gastroenterol (2015) 21(26):7933-43. doi: 10.3748/ wjg.v21.i26.7933

4. Jiang X, Tseng CC, Bernstein L, Wu AH. Family History of Cancer and Gastroesophageal Disorders and Risk of Esophageal and Gastric Adenocarcinomas: A Case-Control Study. BMC Cancer (2014) 14:60. doi: 10.1186/1471-2407-14-60

5. Su H, Hu N, Shih J, Hu Y, Wang QH, Chuang EY, et al. Gene Expression Analysis of Esophageal Squamous Cell Carcinoma Reveals Consistent Molecular Profiles Related to a Family History of Upper Gastrointestinal Cancer. Cancer Res (2003) 63(14):3872-6.

6. Lin Y, Wu C, Yan W, Guo S, Lin S, Liu B. Sociodemographic and Lifestyle Factors in Relation to Gastric Cancer in a High-Risk Region of China: A Matched Case-Control Study. Nutr Cancer (2020) 72(3):421-30. doi: 10.1080/ 01635581.2019 .1638425

7. Yang H, Zhang S, Yan H, Wang J, Fan J, Qiao Y, et al. Fresh Fruit Consumption may Decrease the Long-Term Risk of Esophageal Cancer Mortality: A 30-Year Follow-Up Study in the Linxian Dysplasia Nutrition Intervention Trial (NIT). Thorac Cancer (2020) 11(7):1918-26. doi: 10.1111/ 1759-7714.13482

8. Wood ME, Kadlubek P, Pham TH, Wollins DS, Lu KH, Weitzel JN, et al. Quality of Cancer Family History and Referral for Genetic Counseling and Testing Among Oncology Practices: A Pilot Test of Quality Measures As Part of the American Society of Clinical Oncology Quality Oncology Practice Initiative. J Clin Oncol (2014) 32(8):824-9. doi: 10.1200/JCO.2013.51.4661

9. Stoffel EM, Mangu PB, Gruber SB, Hamilton SR, Kalady MF, Lau MWY, et al. Hereditary Colorectal Cancer Syndromes: American Society of Clinical Oncology Clinical Practice Guideline Endorsement of the Familial RiskColorectal Cancer: European Society for Medical Oncology Clinical Practice Guidelines. J Clin Oncol (2015) 33(2):209-17. doi: 10.1200/JCO.2014.58.1322

10. $\mathrm{Hu} \mathrm{N}$, Dawsey SM, Wu M, Bonney GE, He LJ, Han XY, et al. Familial Aggregation of Oesophageal Cancer in Yangcheng County, Shanxi Province, China. Int J Epidemiol (1992) 21(5):877-82. doi: 10.1093/ije/21.5.877

11. Wen D, Shan B, Wang S, Zhang L, Wei L, Zhou W, et al. A Positive Family History of Esophageal/Gastric Cardia Cancer With Gastric Cardia Adenocarcinoma Is Associated With a Younger Age at Onset and More Likely With Another Synchronous Esophageal/Gastric Cardia Cancer in a Chinese High-Risk Area. Eur J Med Genet (2010) 53(5):250-5. doi: 10.1016/ j.ejmg.2010.06.011

\section{ACKNOWLEDGMENTS}

Thanks to the participants and health workers of the Linxian NIT study for their contributions. Thanks to Yin Jian from the Department of Epidemiology, Cancer Hospital, Chinese Academy of Medical Sciences for providing assistance with statistical analysis.

\section{SUPPLEMENTARY MATERIAL}

The Supplementary Material for this article can be found online at: https://www.frontiersin.org/articles/10.3389/fonc.2021.605106/ full\#supplementary-material

12. Wen D, Wang S, Zhang L, Zhang J, Wei L, Zhao X. Differences of Onset Age and Survival Rates in Esophageal Squamous Cell Carcinoma Cases With and Without Family History of Upper Gastrointestinal Cancer From a HighIncidence Area in North China. Fam Cancer (2006) 5(4):343-52. doi: 10.1007/ s10689-006-0004-x

13. Yaghoobi M, Bijarchi R, Narod SA. Family History and the Risk of Gastric Cancer. Br J Cancer (2010) 102(2):237-42. doi: 10.1038/sj.bjc.6605380

14. Murphy G, Fan JH, Mark SD, Dawsey SM, Selhub J, Wang J, et al. Prospective Study of Serum Cysteine Levels and Oesophageal and Gastric Cancers in China. Gut (2011) 60(5):618-23. doi: 10.1136/gut.2010.225854

15. Wang SM, Taylor PR, Fan JH, Pfeiffer RM, Gail MH, Liang H, et al. Effects of Nutrition Intervention on Total and Cancer Mortality: 25-Year Post-Trial Follow-Up of the 5.25-Year Linxian Nutrition Intervention Trial. J Natl Cancer Inst (2018) 110(11):1229-38. doi: 10.1093/jnci/djy043

16. Taylor PR, Li B, Dawsey SM, Li JY, Yang CS, Guo W, et al. Prevention of Esophageal Cancer: The Nutrition Intervention Trials in Linxian, China. Linxian Nutrition Intervention Trials Study Group. Cancer Res (1994) 54(7 Suppl):2029s-31s.

17. Dhillon PK, Farrow DC, Vaughan TL, Chow WH, Risch HA, Gammon MD, et al. Family History of Cancer and Risk of Esophageal and Gastric Cancers in the United States. Int J Cancer (2001) 93(1):148-52. doi: 10.1002/ijc.1294

18. Lagergren J, Ye W, Lindgren A, Nyrén O. Heredity and Risk of Cancer of the Esophagus and Gastric Cardia. Cancer Epidemiol Biomarkers Prev (2000) 9 (7):757-60.

19. Yang L, Ji Y, Chen L, Li M, Wu F, Hu J, et al. Genetic Variability in LMP2 and LMP7 Is Associated With the Risk of Esophageal Squamous Cell Carcinoma in the Kazakh Population But Is Not Associated With HPV Infection. PloS One (2017) 12(10):e0186319. doi: 10.1371/journal.pone.0186319

20. Wang Y, Vogelsang M, Schäfer G, Matejcic M, Parker MI. MicroRNA Polymorphisms and Environmental Smoke Exposure as Risk Factors for Oesophageal Squamous Cell Carcinoma. PloS One (2013) 8(10):e78520. doi: 10.1371/journal.pone.0078520

21. Zaitlen N, Kraft P, Patterson N, Pasaniuc B, Bhatia G, Pollack S, et al. Using Extended Genealogy to Estimate Components of Heritability for 23 Quantitative and Dichotomous Traits. PloS Genet (2013) 9(5):e1003520. doi: 10.1371/journal.pgen.1003520

22. Qiuling S, Dezhong X, Changsheng S, Liangso L. Study on Family Aggregation of Esophageal Cancer in Linzhou City. J Prev Med Chin PLA (2001) 19 (2):269-70. doi: 10.13704/j.cnki.jyyx.2001.02.010

23. Kato I, Tominaga S, Matsumoto K. A Prospective Study of Stomach Cancer Among a Rural Japanese Population: A 6-Year Survey. Jpn J Cancer Res (1992) 83(6):568-75. doi: 10.1111/j.1349-7006.1992.tb00127.x

24. Song H, Ekheden IG, Ploner A, Ericsson J, Nyren O, Ye W. Family History of Gastric Mucosal Abnormality and the Risk of Gastric Cancer: A PopulationBased Observational Study. Int J Epidemiol (2018) 47(2):440-9. doi: 10.1093/ ije/dyx238

25. Safaee A, Moghimi-Dehkordi B, Fatemi SR, Maserat E, Zali MR. Family History of Cancer and Risk of Gastric Cancer in Iran. Asian Pac J Cancer Prev (2011) 12(11):3117-20. 
26. García-González MA, Quintero E, Bujanda L, Nicolás D, Benito R, Strunk M, et al. Relevance of GSTM1, GSTT1, and GSTP1 Gene Polymorphisms to Gastric Cancer Susceptibility and Phenotype. Mutagenesis (2012) 27(6):771-7. doi: 10.1093/mutage/ges049

27. Figueiredo C, Camargo MC, Leite M, Fuentes-Pananá EM, Rabkin CS, Machado JC. Pathogenesis of Gastric Cancer: Genetics and Molecular Classification. Curr Top Microbiol Immunol (2017) 400:277-304. doi: 10.1007/978-3-319-50520-6_12

28. Chen T, Cheng H, Chen X, Yuan Z, Yang X, Zhuang M, et al. Family History of Esophageal Cancer Increases the Risk of Esophageal Squamous Cell Carcinoma. Sci Rep (2015) 5:16038. doi: 10.1038/srep16038

29. Ni YC. Study on Association Between Family History of Tumors and Gatric Cancer Risk. Shandong: Shandong University (2018).

30. Inoue M, Tajima K, Hirose K, Kuroishi T, Gao CM, Kitoh T. Life-Style and Subsite of Gastric Cancer-Joint Effect of Smoking and Drinking Habits. Int J Cancer (1994) 56(4):494-9. doi: 10.1002/ijc.2910560407

31. Huyan S, Xiaoyan X, Leping F, Puwen H. Comparison of Clinicopathological Features and Prognosis of Radical Resection for Cardia Cancer and NonCardia Cancer. J Med Internet Res (2016) 45(5):145-8. doi: 10.1097/ MD.0000000000001386

32. Hemminki K, Sundquist J, Ji J. Familial Risk for Gastric Carcinoma: An Updated Study From Sweden. Br J Cancer (2007) 96(8):1272-7. doi: 10.1038/ sj.bjc. 6603722

33. Lissowska J, Groves FD, Sobin LH, Fraumeni JF Jr, Nasierowska-Guttmejer A, Radziszewski J, et al. Family History and Risk of Stomach Cancer in Warsaw, Poland. Eur J Cancer Prev (1999) 8(3):223-7. doi: 10.1097/00008469199906000-00010

34. Gao Y, Hu N, Han X, Giffen C, Ding T, Goldstein A, et al. Family History of Cancer and Risk for Esophageal and Gastric Cancer in Shanxi, China. BMC Cancer (2009) 9:269. doi: 10.1186/1471-2407-9-269

35. Yatsuya H, Toyoshima H, Mizoue T, Kondo T, Tamakoshi K, Hori Y, et al. Family History and the Risk of Stomach Cancer Death in Japan: Differences by Age and Gender. Int J Cancer (2002) 97(5):688-94. doi: 10.1002/ijc.10101

36. Yazdanbod A, Nasseri-Moghaddam S, Malekzadeh R. Upper Gastrointestinal Cancer in Ardabil, North West of Iran: A Review. Arch Iran Med (2004) 7 (3):173-7.
37. Eom BW, Joo J, Kim S, Shin A, Yang H-R, Park J, et al. Prediction Model for Gastric Cancer Incidence in Korean Population. PloS One (2015) 10(7): e0132613. doi: 10.1371/journal.pone.0132613

38. Xu Q, Liu JW, Yuan Y. Comprehensive Assessment of the Association Between miRNA Polymorphisms and Gastric Cancer Risk. Mutat Res Rev Mutat Res (2015) 763:148-60. doi: 10.1016/j.mrrev.2014.09.004

39. Xu Q, Dong Q, He C, Liu W, Sun L, Liu J, et al. A New Polymorphism Biomarker rs629367 Associated With Increased Risk and Poor Survival of Gastric Cancer in Chinese by Up-Regulated miRNA-let-7a Expression. PloS One (2014) 9(4):e95249. doi: 10.1371/journal.pone.0095249

40. Yang F, Wei K, Qin Z, Shao C, Shu Y, Shen H. Association Between TNF- $\alpha-308$ G/ A Polymorphism and Esophageal Cancer Risk: An Updated Meta-Analysis and Trial Sequential Analysis. J Cancer (2019) 10(5):1086-96. doi: 10.7150/jca.29390

41. Zhang Y, Sun LP, Xing CZ, Xu Q, He CY, Li P, et al. Interaction Between GSTP1 Val Allele and H. Pylori Infection, Smoking and Alcohol Consumption and Risk of Gastric Cancer Among the Chinese Population. PloS One (2012) 7(10):e47178. doi: 10.1371/journal.pone.0047178

42. Zhao F, Su J-F, Lun S-M, Hou Y-J, Duan L-J, Wang N-C, et al. Association Between Polymorphisms in the CYP1A1, CYP2E1 and GSTM1 Genes, and Smoking, Alcohol and Upper Digestive Tract Carcinomas in a High-Incidence Area of Northern China. Oncol Lett (2019) 18(2):1267-77. doi: 10.3892/ ol.2019.10455

43. Kerber RA, Slattery ML. Comparison of Self-Reported and Database-Linked Family History of Cancer Data in a Case-Control Study. Am J Epidemiol (1997) 146(3):244-8. doi: 10.1093/oxfordjournals.aje.a009259

Conflict of Interest: The authors declare that the research was conducted in the absence of any commercial or financial relationships that could be construed as a potential conflict of interest.

Copyright (c) 2021 Yang, Wang, Zhang, Fan, Qiao and Taylor. This is an open-access article distributed under the terms of the Creative Commons Attribution License (CC BY). The use, distribution or reproduction in other forums is permitted, provided the original author(s) and the copyright owner(s) are credited and that the original publication in this journal is cited, in accordance with accepted academic practice. No use, distribution or reproduction is permitted which does not comply with these terms. 